\title{
A perspectiva canhota de um emigrado russo: expressão homoerótica na poesia de Valério Pereliéchin (1953-1992)
}

\author{
CARLOS CORTEZ MINCHILLO \\ Dartmouth College
}

\begin{abstract}
This article examines the poetry of Valério Pereliéchin (Valerii Pereleshin in his native Russian), a gay writer and translator who produced a significant collection of homoerotic poems in Portuguese over the second half of the twentieth century. Pereliéchin was born in Russia in 1913 and soon migrated to China, where he lived among other Russian émigrés in the town of Harbin. In 1953, after a failed attempt to go to the United States, he and his mother arrived in Brazil, where he lived -unnoticed by local writers and artists- for almost forty years. A central issue in Pereliéchin's personal life, homosexuality gradually became the core theme of his work. Through the idea of "existential lefthandedness," Pereliéchin challenged heteronormativity, especially by refuting what Lee Edelman has called "reproductive futurity." I argue that Pereliéchin's alternative way of tackling the past and future stems from the intersectionality of his experiences as a gay man and an émigré.
\end{abstract}

Keywords: Brazilian poetry, Russian poetry, migration, dictatorship, homoerotic

Na edição de outubro de 1979 do periódico brasileiro gay Lampião da esquina foram publicados dois sonetos de um certo Valério Pereléchin. Os textos tratam, 
via imagens de sacrilégio e canibalismo, do desejo suscitado pelos corpos de “jovens reis" que, de sua parte, parecem ignorar ou rejeitar os apelos homoeróticos do poeta: "Três carnes, três tamanhos, três sabores, / Pregusto-os com o meu olhar faminto,/ Quando se afastam pelos corredores" ("O canibal"). ${ }^{1}$ Em breve nota introdutória sobre "o misterioso poeta Pereléchin," Glauco Mattoso observava que o autor, poeta russo-sino-brasileiro, "permanece ignorado entre nós, embora esteja radicado no Rio há 25 anos" (14). O silêncio em torno do autor e de sua obra perdura e é ainda mais intrigante quando se sabe que Pereliéchin (grafia adotada em seu único livro publicado em português) passou quase metade de sua vida no Rio de Janeiro. Durante 39 anos viveu e produziu literatura no Brasil, onde em 1992 morreu, pobre e solitário, no Retiro dos Artistas, em Jacarepaguá. Celebrado como um dos mais notáveis poetas russos do século XX por Simon Karlisnky e Alexis Rannit, importantes nomes dos estudos eslavos na academia norte-americana, Pereliéchin se destaca também por ter produzido e publicado, em russo e em português, uma ampla lírica homoerótica, a despeito da resistência que a identidade homossexual e as relações homoafetivas despertavam nos círculos internacionais de emigrados russos (ao qual Pereliéchin manteve-se conectado) e do moralismo conservador e repressivo da ditadura militar no Brasil (1964-1985).

A poética erótica de Pereliéchin, segundo o escritor e acadêmico Yurii Ivask, é sombria em suas "camadas mais baixas" e apresenta tensão e força que não se encontram facilmente no "amor comum" (4). Mais que isso, os poemas de Pereliéchin, especialmente os que se encontram em Ariel (1976), Nos odres velhos (1983) e Poema sem objeto (1989), revelam uma profunda e libertária crença na multiplicidade das identidades sexuais e propõem uma crítica, frequentemente sarcástica, sobre a heteronormatividade. Na poética de Pereliéshin verifica-se uma trajetória, não necessariamente retilínea, que vai do

\footnotetext{
${ }^{1}$ Os poemas de Pereliéchin originalmente escritos em português foram transcritos de Nos odres velhos e serão referenciados apenas por seus títulos e páginas. Os demais poemas, publicados em inglês ou russo, serão referenciados pelos títulos em português seguidos da indicação da obra em que foram localizados. As versões em inglês e seus títulos foram livremente traduzidos ao português por mim. Os poemas em russo foram traduzidos, sem compromisso de métrica ou rima, por Alexander B. Johnson. Agradeço a The Leslie Center for the Humanities em Dartmouth College o generoso apoio financeiro dado a Johnson para a realização deste projeto. Agradeço igualmente a Alceste Pinheiro, Antônio Carlos Moreira, Glauco Mattoso, Jan Paul Hinrichs, João Silvério Trevisan, Luc Jean Beaudoin e Thomas Bruein pela gentileza de trocar ideias e compartilhar informações sobre a obra e a vida de Pereliéchin.
} 
recalque à aceitação dos impulsos homossexuais. Se ainda em sua juventude na China Pereliéchin buscou a sublimação da homossexualidade no exercício religioso e no prazer estético, a partir da década de 1970 ele vê-se no direito de, como gay, "rejeitar o mundo" e defender o lugar excêntrico-mas lícito- de sua identidade e de seus desejos (Bakich 208). Como registrou em carta de 1981, chega à conclusão de que "a visão de que o amor gay é 'sujo,' 'vicioso' e infame está a um passo do 'Heil Hitler'” (Bakich 215). Esse percurso existencial e poético pode ser acompanhado pela imagem do "canhoto" que percorre sua obra. Em poema de meados de 1930, a mão esquerda surge como "inimiga" (Bakich 215), enquanto em "O destino" (1979) a mão esquerda é estigma, mas não deformidade ou afronta: "Não é doença (que não pareço doente) / Nem crime aquele fenômeno ignoto: / o isófilo é da raça do canhoto / No campo dos instintos e da mente" (22).

A canhotice espiritual de Pereliéchin, sentida como tendência inata, definelhe uma posição no mundo-incomum, mas não anormal-e constitui obviamente uma forma de registrar e contestar, com outra mão e outra sensibilidade, esse mesmo mundo. Como veremos com mais detalhes ao longo deste estudo, esse ponto de vista descentrado foi naturalmente potencializado pela condição de duplo emigrado (da Rússia para a China, e da China para o Brasil), favorecendo o surgimento, corajoso para a época, de uma voz poética profunda e criativamente questionadora do arranjo social estruturado pela heterossexualidade. Nesse sentido, sua obra encerra um gesto político, se entendemos com Lauren Berlant que "política sexual [...] gera melhores cenários para abrigar sua perturbadora descompostura" (20). Entretanto, amplamente ignorada até hoje, a poesia de Pereliéchin não chegou a repercutir na esfera pública como seria desejável e, infelizmente, sua visão queer sobre a sexualidade e os gêneros contribuiu menos do que poderia para a diversificação do repertório simbólico de identidades e atitudes no escopo da literatura em português.

\section{Pereliéchin: o poeta brasileiro que veio da Rússia}

O percurso de Pereliéchin até chegar ao Brasil é uma enfiada de peripécias, narradas pelo próprio poeta em depoimento de 1974 e exaustivamente investigadas por sua biógrafa, Olga Bakich, e pelo bibliotecário e estudioso de 
literaturas eslavas Jan Paul Hinrichs. ${ }^{2}$ Em 1920, Valério e seu irmão Victor foram levados para Harbin, no extremo leste da China, por sua mãe, Eugênia Burakova. Ao emigrar, ela rompia um casamento infeliz e tentava escapar às agruras da guerra civil na Rússia e à tomada de poder pelos bolcheviques. Durante os trinta e dois anos seguintes, Pereliéchin viveu em Beijing, Shangai e Tientsin.

Graduou-se em Direito, consagrou-se monge e trabalhou como tradutor. Viveu suas primeiras experiências homoafetivas, de encontros casuais a grandes paixões. Na década de 1950, tentou emigrar para os Estados Unidos mas, possivelmente por haver obtido um passaporte soviético e ter feito traduções para a agência TASS, havia suspeitas de que fosse um agente comunista, e sua solicitação de visto foi diversas vezes negada. Como alternativa, o irmão Victor conseguiu permissão para a mãe e Valério seguirem para o Brasil na condição de refugiados. Com isso, solucionava-se uma situação de vida que havia se tornado mais difícil com a vitória dos comunistas na China e com episódios homofóbicos de que Pereliéchin e um de seus amantes foram vítimas e que resultaram, inclusive, em algumas semanas de prisão. A chegada ao "sonoro" Brasil, "terra de flores" (Bakich 143), parece então ter representado um alívio. Mesmo que Pereliéchin tenha ainda tentado emigrar para os Estados Unidos, onde ele acreditava que poderia seguir uma carreira acadêmica, ele afirmou em uma carta que "gost[ava] de quase tudo aqui [no Brasil], as pessoas descontraídas, clima maravilhoso, bela natureza, constelações, feriados, caras" (Bakich 144). Não espanta que o carnaval do Rio de Janeiro tenha logo chamado sua atenção: "três quartos dos homens, com saias e maquiagem, colocam falsos peitos e caminham balançando as ancas e fazendo gestos indecentes. Uma disfarçada feminilidade da raça latina, escondida sob inevitáveis bigodes, vêm à tona" (Bakich 144).

Naturalizado em 1958, Pereliéchin instruiu-se sobre a história do Brasil e acompanhava com interesse o que acontecia no país, como se depreende de sua correspondência. Ele considerava-se um poeta brasileiro que, por acaso, expressava-se em russo (Karlinsky, Russian Culture 316). Mas nem isso era toda a verdade: chegando ao país em 1953 com conhecimento apenas rudimentar do

\footnotetext{
${ }^{2}$ A própria obra de Pereliéchin é fonte importante de informações biográficas. Como se confirma em sua correspondência, o escritor faz em seus poemas explícitas alusões a episódios de sua vida e, segundo sua definição, o poeta é "uma espécie de câmera portátil para fazer filmes" (Bakich 195). Na apresentação de Nos odres velhos, Pereliéchin escreve ainda que o poeta "[t]ranforma em objetos de arte algumas circunstâncias da própria vida, misturadas com seus próprios impulsos reprimidos" (8).
} 
idioma local, 30 anos depois o emigrado publicou versos escritos diretamente em português. Em Nos odres velhos (1983), Pereliéchin reúne 66 textos de sua autoria - a maioria sonetos metrificados e rimados - e algumas traduções do inglês, do russo e do chinês para o idioma de Camões, que ele disse ter aprendido graças a leituras e "conversações com brasileiros" (Nos odres 7). Pereliéchin ganhou intimidade com a literatura brasileira e chegou a publicar na Alemanha Iuzhnyi krest (Cruzeiro do Sul, 1978), antologia que compreende traduções suas para o russo de 53 poetas brasileiros, entre eles Mário de Andrade, Cecília Meireles, Manuel Bandeira, Machado de Assis, Augusto dos Anjos, Guilherme de Almeida, Álvares de Azevedo e Tomás Antônio Gonzaga. Confessou amar Camões, mas sentir-se mais próximo de Fernando Pessoa: "parece que ele não dedicou poemas a mulheres" (Carta a Peter Lapiken 31 out. 1976). Suas preferências literárias em português despontam em alguns de seus poemas:

$\mathrm{O}$ agitar da vela latina

e o tremular do sinal de Malta, Eu os encontro em Tito de Barros

e Olavo Bilac.

As úmidas florestas do Brasil, o cálido charme das orquídeas, Eu o encontro em Cecília, a incomparável Meireles. (Bakich 231)

Foi ainda durante seus anos no Brasil que Pereliéchin publicou, na Alemanha, França e Estados Unidos, nove de seus 13 livros de poesia em russo, além de traduzir do chinês para o russo e de ter colaborado em revistas e jornais dos círculos de emigrados russos em Nova York, Philadelphia, Paris e Frankfurt. Mas quase nenhuma referência existe na produção acadêmica brasileira sobre Pereliéchin e, na imprensa, apenas outras quatro menções, além dos poemas publicados no Lampião da esquina. ${ }^{3}$

${ }^{3}$ As buscas por "Pereliéchin," "Pereliechin," "Perelechin" e "Pereleshin" nos catálogos de cinco bibliotecas universitárias brasileiras (USP, Unicamp, UFRJ, UFMG e UFRGS) não retornaram nenhum resultado. No catálogo online da Biblioteca Nacional do Rio de Janeiro consta apenas o livro Cânticos de Alexandria, tradução de Pereliéchin dos poemas do poeta russo Mikhail Kuzmin. Quanto aos jornais, ver "Cruzeiro do Sul;" Wyler; Junqueira; e "A língua portuguesa nos versos de um poeta russo." 
Quanto aos escritores brasileiros, o desconhecimento parece ter sido geral, até mesmo entre os poetas traduzidos por Pereliéchin que estavam vivos àquela época. ${ }^{4}$ Segundo ele, os escritores brasileiros "est[avam] interessados neles mesmos, em suas publicações, e em seus círculos. Literatura russa aqui não é menos exótica que a chinesa. Todo mundo fica 'curioso' e isso é o máximo que acontece" (Bakich 245). Em "Difícil de convencer" (1975), Pereliéchin emprega a metalinguagem para resumir a situação do poeta num país que o ignora: "Um poeta / Um certo Pereliéchin? / De que adianta ter vindo de Harbin?” (Bakich 169). Em nota escrita a mão em um recorte de jornal sobre Joaquim Cardozo, Pereliéchin comenta que este teria sido "o único grande poeta brasileiro que me honrou com sua amizade" (Hinrichs, Catalogue 110).

Parte desse isolamento pode ter se originado do temperamento de Pereliéchin. Vivendo recluso com a mãe (até a morte dela em 1980) em um apartamento repleto de livros, pratos sujos e cinzeiros usados, Pereliéchin, nas palavras de Winston Leyland, era "agradável, mas excêntrico" ("Valery Pereleshin" 183). O poeta mantinha com Victor, o irmão homofóbico em grande parte responsável por seu sustento, um relacionamento tenso e ganhou vários desafetos na comunidade internacional de emigrados, graças a seus comentários sobre aqueles com quem havia convivido na cidade chinesa de Harbin. A biógrafa Olga Bakich opina que, ao longo da vida, Pereliéchin tornou-se amargo em função da homofobia, injustiças e dificuldades que teve de enfrentar (270). ${ }^{5}$

Também fora do Brasil, Pereliéchin parece ter tido poucos leitores, apesar dos livros publicados e da inclusão de alguns de seus poemas em três antologias de poesia russa lançadas fora da União Soviética (Bakich 248). Em primeiro lugar porque, segundo Simon Karlinsky, apesar de a melhor literatura russa pósrevolução ter sido produzida em grande parte por emigrados, na União Soviética

\footnotetext{
${ }^{4}$ Em mensagem eletrônica, o pesquisador e bibliotecário Jan Paul Hinrichs, responsável por levar a maior parte do acervo de Pereliéchin para a Universidade de Leiden, na Holanda, informou-me que em suas cartas Pereliéchin jamais mencionou conexões com escritores brasileiros. Também na listagem do acervo do poeta em Leiden, praticamente não há indícios de correspondência com artistas, escritores ou intelectuais brasileiros.

${ }^{5}$ A restrita inserção de Pereliéchin nos meios artísticos e intelectuais do Brasil merece ainda maior investigação e se torna ainda mais evidente na comparação com o caso do romeno Stefan Baciu, outro poeta naturalizado brasileiro que, fugindo à perseguição comunista no leste europeu, chegou ao Brasil em 1949, onde viveu até 1962. Apesar de menor permanência no país, Baciu, que trabalhou para o jornal Tribuna da imprensa e foi secretário da seção brasileira do Congresso pela Liberdade de Cultura, foi capaz de estabelecer uma ampla rede de conexões e amizades entre escritores, jornalistas e intelectuais no Brasil.
} 
esses escritores não eram considerados russos, e suas obras não eram estudadas e nem podiam circular dentro do território soviético, sendo lidas apenas por um seleto público da diáspora ("A Hidden Masterpiece" 37). Assim, os livros de Pereliéchin, sempre impressos com enormes dificuldades financeiras e em pequenas tiragens, mereceram reconhecimento apenas entre a comunidade russa na China (onde ele publicou seus primeiros quatro livros, entre 1937-1944), alguns acadêmicos do mundo ocidental interessados na poesia eslava (muitos deles igualmente emigrados) e um ou outro leitor soviético que lograva obter exemplares clandestinos. Na União Soviética, além do ostracismo imposto aos escritores da diáspora até por volta de 1980, Pereliéchin teve ainda que transpor uma segunda fronteira, igualmente excludente, criada pelas barreiras sociais contra a homossexualidade e sua expressão na vida e na arte.

\section{O poeta gay e a "psicologia brasileira"}

Se na década de 1930, vivendo em Harbin, Pereliéchin chega a escrever que "o amor é o começo da queda / e a voz da carne é a voz das mentiras" (Bakich 47), depois de suas primeiras experiências sensuais e encontros amorosos com homens Pereliéchin afasta-se da retórica condenatória da religião — ele chegou a exercer funções sacerdotais - e progressivamente assume sua homossexualidade de forma bastante pública, tratando-a explicitamente em sua poesia e em sua correspondência, especialmente depois de sua chegada ao Brasil. Em carta de 1974 ao poeta russo emigrado Iurii Ivask, Pereliéchin confirma que seus primeiros textos homoeróticos teriam sido muito mais explícitos se escritos sob a influência da "psicologia brasileira" (Li e Sylvester). Em um poema dessa mesma época conclui que "China é amor, Brasil é liberdade" ("O pária," Li e Sylvester).

Pode soar surpreendente essa avaliação favorável do clima social no Brasil durante anos de grande repressão política exercida pelo regime autoritário civilmilitar instituído em 1964. Pereliéchin talvez chegasse a essa conclusão comparando a relativa visibilidade e limitada tolerância da vida gay no Rio de Janeiro dos anos 1960 e 70 (Green 262 e 400; Lopes 25) às suas vivências na China décadas antes e às reações mais conservadoras de alguns de seus leitores pertencentes à comunidade internacional de emigrados russos. Comentando aspectos negativos do Brasil—“corrupção inflação e chauvinismo"-Pereliéchin 
não faz menção à situação dos homossexuais e conclui que os problemas do país se apresentam no âmbito da economia e da política, mas "não são sentidos na vida diária" (Bakich 144).

Claro está que, com o endurecimento do regime a partir do Ato Institucional 5 de 1968, a perseguição político-ideológica oficial contra os movimentos de resistência infundiu no país um reacionarismo em defesa dos "bons costumes". Por exemplo, em 1972 o Ministro da Justiça Alfredo Buzaid explicava que o comunismo "[m]ina a família através de desenfreada propaganda do sexo, do amor livre e da obscenidade" (Carvalho 28n12). Mas, como explica James Green, parecia haver algum limite na capacidade censória do poder ditatorial, que se ocupou sobretudo das manifestações literárias e artísticas, de modo que, em comparação, "o território social das casas de banho e pistas de dança [frequentadas pelos homossexuais] era relativamente insignificante" (399). E mesmo no que se refere às atividades artísticas, nem tudo pôde ser controlado: a contestação dos papéis de gênero, dentro de um clima social de irreverência e desbunde promovido pela contracultura, desponta não só nas manifestações artísticas marginais, mas chega mesmo à cultura pop e à grande mídia, como atesta o surgimento e sucesso do grupo teatral Dzi Croquetes, do cantor Ney Matogrosso e da Tropicália (Trevisan 166). O próprio jornal gay Lampião da esquina (1978-81), que publicou os dois sonetos de Pereliéchin, é parte dessa atmosfera que apontava para um país que a duras penas resistia às pressões da ditadura. Pelo que se lê em sua correspondência e pelo que se deduz de poemas que permitem uma leitura biográfica, Pereliéchin manteve no Brasil uma vida sexual bastante ativa e só de relance registrou a repressão e violência contra os homossexuais que também caracterizou aquele momento político-institucional brasileiro. Em "Amendoim," o eu lírico refere-se aos cercos policiais nos espaços de convivência gay como a galeria Alaska, em Copacabana: "Devo escutar a rouquidão das vozes, / Fugindo à blitz na galeria 'Alaska"” (40).

Como leitor, é notável o interesse de Pereliéchin pela literatura gay internacional. Em um breve ensaio, faz uma leitura queer de Pushkin, comentando textos homoeróticos do poeta russo que, mesmo sendo "o mais cissexual ['straight'] possível," demonstrava notável tolerância e "admitia a possibilidade de qualquer 'desvio"” (Leyland, Gay Roots 649). Como tradutor, verte para o português as Canções de Alexandria, do poeta Mikhail Kuzmin, que na São Petersburgo do começo do século XX viveu publicamente sua 
homossexualidade e que é autor de Krylya (Asas, 1906), considerado o primeiro romance russo centrado numa relação homoafetiva. Em carta a Peter Lapiken, seu amigo de Harbin emigrado para os Estados Unidos, Pereliéchin se defende dos possíveis ataques ao seu Poema sem objeto, mencionando um poema de W. H. Auden que descreve um encontro sexual fortuito entre homens: "Se 'Platonic Blow' chegou a ser publicado por alguém, então não haveria por que se preocupar com o seu poema" (13 abril 1976).

Os ventos transnacionais da contracultura e do movimento gay nos anos 1970 certamente promoveram um contexto um pouco mais favorável para o lirismo homoerótico de Pereliéchin, com a criação de canais de circulação específicos destinados a uma audiência gay ainda restrita mas receptiva. Nesse momento ele conseguiu voltar a publicar, colaborando nos mais importantes veículos da imprensa gay norte-americana, como Gay Sunshine e Christopher Street. Em "To One Who Confessed," chega mesmo a referir-se ao escritor e editor Winston Leyland, a quem conheceu pessoalmente no Rio, fazendo uma apologia, rara em sua obra, do ativismo gay:

Não estamos sós. Creia-me, existem milhões

Que seguirão Leyland na sua justa luta

Por nossa igualdade, por legislação decente

E pelo direito de vivermos e sermos nós mesmos.

A partir dessa época, textos de Pereliéchin foram incluídos em antologias de literatura gay lançadas nos Estados Unidos, duas delas editadas pelo próprio Leyland. No Brasil, os dois sonetos publicados pelo Lampião da esquina, o primeiro periódico gay de alcance nacional, são (salvo engano) os únicos poemas de Pereliéchin jamais divulgados pela imprensa, especializada ou não.

Entretanto, é mais que sabido que, fora de certos nichos engajados e progressistas, a temática homoerótica na literatura e a visibilidade dos homossexuais na vida pública provocavam (como provocam ainda hoje) forte rejeição, seja no Brasil, na União Soviética ou entre os emigrados russos. Na União Soviética, desde meados da década de 1930 haviam sido instituídas leis que criminalizaram a homossexualidade masculina e, a partir daí, coibiram-se referências à homossexualidade latente de figuras centrais da cultura russa, como Tólstoi e Gógol, e impediu-se a publicação de obras ocidentais de temática 
homossexual de autores como André Gide, Konstantínos Kaváfis, Marcel Proust, Jean Cocteau e James Baldwin (Schuvaloff 16). Os russos da diáspora, muitos fortemente impactados pelos preceitos homofóbicos da Igreja Ortodoxa Russa, não eram em sua maioria mais tolerantes, incluindo aqueles que viviam nos Estados Unidos e na Europa e os que trabalhavam como editores de revistas e jornais da comunidade dos emigrados e na comercialização de obras em russo. Quando Pereliéchin lançou Ariel (1976), um conjunto de 169 sonetos epistolares que equivale a um "inequívoco sair do armário" (Karlinsky, "A Hidden Masterpiece" 38), muitos de seus leitores mais próximos se horrorizaram com a narrativa de seu apaixonamento à distância por um moscovita casado. Segundo Bakich, poetas e críticos estabelecidos da imprensa dos emigrados não se atreveram a escrever resenhas, como se temessem qualquer associação, mesmo indireta, com o livro (211). Karlinsky, que considerou o livro uma "obra prima oculta" em elogioso estudo, comenta que a publicação de Ariel (1976) teria custado a Pereliéchin boa parte de seus poucos leitores e informa que livrarias e agentes que lidavam com livros em russo nas principais cidades norte-americanas se recusaram a comercializar a obra ("A Hidden Masterpiece" 41).

No Brasil, não se esperaria que as obras publicadas em russo tivessem repercussão, mas a inclusão dos dois poemas de Pereliéchin no Lampião da esquina, caso tivessem recebido alguma atenção e caso o campo literário brasileiro estivesse pronto para isso, poderiam ter posto o poeta russo-sinobrasileiro no radar da literatura brasileira, o que não ocorreu. Mesmo quatro anos depois, quando Nos odres velhos vem à luz, a obra não apenas passou quase despercebida, talvez porque publicada por uma pequena editora de textos anarquistas, a Achiamé. As duas únicas resenhas localizadas pela pesquisa não fazem menção - talvez por receio da censura? - ao teor homoerótico da maioria das composições de autoria de Pereliéchin. Aliás, tampouco o autor, na introdução que escreveu para o livro, explicita o lirismo gay que predomina na obra. Possivelmente preferindo ser levado "a sério" como poeta (afinal, a publicação do livro seria uma oportunidade única de ganhar visibilidade na vida literária brasileira), Pereliéchin sai pela tangente, entendendo o trabalho do poeta como a criação de "um mundo imaginário," transformando "em objetos de arte algumas circunstâncias da própria vida" (Nos odres 7).

Ivan Junqueira, em breve artigo que aborda o lançamento no mercado de três obras de poesia em tradução, destaca em Nos odres velhos especialmente a 
tradução de "Antinous," de Fernando Pessoa, que Junqueira desaprova pela excessiva liberdade que Pereliéchin tomou em relação ao original inglês. Nada se diz sobre o conteúdo do poema, que reconta liricamente o amor do imperador Adriano por seu jovem escravo. É certo que, sendo ele mesmo poeta e tradutor, Junqueira analisa sobretudo aspectos técnicos das três obras de tradução que resenha, interrogando a ideia de fidelidade ao original e flagrando o que considera acertos e deslizes de linguagem e de tom. Mas é curioso que, no fechamento da resenha, Junqueira extrapole o foco de seu texto, cujo subtítulo é "três exemplos de como traduzir e trair os grandes poetas," e encontre espaço para tratar dos poemas de autoria do próprio Pereliéchin. O crítico arremata acidamente que, "a julgar pelos sonetos que o autor escreveu em português, cumpre assinalar que o gênero fica aqui reduzido a um simples e vulgar esquema métrico." Ainda sem tirar os olhos da dimensão estritamente estrutural, Junqueira passa por cima do fundo temático da obra (o que lhe permitiria relacioná-la a "Antinous"), a não ser que, ao empregar o termo "vulgar," o crítico não quisesse sugerir apenas a banalidade das formas poéticas empregadas por Pereliéchin, mas estivesse fazendo uma velada apreciação moral, voluntária ou não, sobre os poemas homoeróticos de Nos odres velhos.

A matéria "A língua portuguesa nos versos de um poeta russo," de $O$ Estado de S. Paulo, igualmente evita abordar o tema predominante na coletânea de Pereliéchin. Ao informar o lançamento de Nos odres velhos, insiste nos aspectos técnicos do livro: refere-se aos sonetos "metrificados à maneira de Petrarca," aos rondós e triolés, e às traduções em que se mantêm do original a métrica e a rima. A resenha também traz elementos biográficos do autor, construindo um perfil genericamente "inusitado," mais pelas perambulações do poeta do que por suas vivências emocionais ou por sua expressão poética: "aos 70 anos tem muitas histórias repletas de aventuras dentro de sua geografia existencial. Afinal, ele nasceu nas planícies geladas da Sibéria, viveu durante anos na China, onde foi monge ortodoxo, e há 30 anos mora no Brasil." Segundo o texto, as duas paixões do poeta são de ordem linguística: "rimas" e "traduções." Não que esses aspectos não correspondessem a interesses autênticos de Pereliéchin. $\mathrm{O}$ apuro técnico foi sempre uma preocupação do poeta que, nessa ocasião, reitera sua total preferência pelo verso rimado. Mas o destaque para os aspectos estritamente formais talvez fosse um artifício de recalque-do próprio Pereliéchin? Do jornalista e/ou do veículo?-ao homolirismo presente em Nos odres velhos. O 
valor verdadeiramente revolucionário da poesia de Pereliéchin-escrever da perspectiva gay sobre amores, frustrações, ciúmes, beleza, velhice, flertes, prostituição, corpos que se entregam e que se negam- é suprimido em nome da "curiosidade" de um russo que escreve em português adotando formas clássicas. Na matéria anônima de $O$ Estado de S. Paulo, a única menção ao conteúdo dos poemas vem de um depoimento do próprio Pereliéchin: "Sempre me defini como poeta neoclassicista e minha poesia é erótica sem ser obscena." Da maneira como foi publicado, o depoimento de Pereliéchin—que, em verdade, não parece ter sido nunca um ativista da causa gay-trata genericamente de "questões filosóficas e religiosas," "conflitos internos" e "confissões íntimas," mas não toca na homossexualidade, como experiência pessoal ou como tema da poesia, o que não deixa, mais uma vez, de causar estranheza, dada a evidência na obra resenhada de um tema que, no mínimo por sua baixa visibilidade nas letras brasileiras de então, mereceria receber algum destaque. Como o autor explica na introdução do livro, o próprio título remete à confluência de tema e forma, sugerindo “"o vinho novo' (tema pouco elaborado por meus predecessores) que fermenta nos 'odres velhos' das formas classicistas" (Nos odres 7).

Do ponto de vista crítico, tratar do odre velho e desprezar o vinho novo foi um lamentável equívoco, ainda que talvez isso se deva a um silenciamento imposto pelas circunstâncias do momento político brasileiro. Tivessem outras possibilidades, outros olhos, mais variados interesses e diferente postura crítica, os resenhistas poderiam, por exemplo, ter situado Pereliéchin em uma vertente da lírica erótica/obscena brasileira, que, da colônia ao século XX, abarca desde poemas de Gregório de Matos até os versos de Mauro Faustino, Roberto Piva, Glauco Mattoso, Paulo Augusto e Valdo Motta. Ou então poderiam tê-lo conectado a uma mais ampla série literária gay que, especialmente a partir de meados da década de 1970, compreendia poemas, contos e romances de autores brasileiros como Cassandra Rios, Aguinaldo Silva, João Silvério Trevisan, Darcy Ribeiro, Caio Fernando Abreu, entre outros (Lopes 126-64; Trevisan 148-59). Mas nada disso aconteceu, desperdiçou-se o momento do lançamento de Nos odres velhos e, até hoje, os estudos de literatura gay brasileira não têm dado notícia da produção de Pereliéchin, esse artífice de formas clássicas que tinha, como apontou Karlinsky, uma "aguda sensibilidade moderna" ("A Hidden Masterpiece" 40) e que produziu, a partir da perspectiva de um homossexual, um significativo e instigante conjunto de homotextos (Lopes 22) em português. 


\section{Do mosteiro à galeria Alaska: as figurações de um gauche}

O percurso poético de Pereliéchin é, como se sugeriu acima, de gradativa, ainda que vacilante, aceitação da própria homossexualidade e, consequentemente, da liberdade de expressar em termos literários não apenas o homoerotismo mas uma perspectiva queer sobre a sociedade heteronormativa. Seus primeiros cadernos de poemas manuscritos já traziam o tema do amor entre homens, mas cercado da sensação de pecado e muitas vezes encoberto por formulações gramaticais em russo que permitem o ocultamento do gênero (Bakich 25 e 45). Em "Le mal invincible," o poeta dilacera o próprio corpo, cortando sua mão pecadora, que, entretanto, ressurge, em sonhos noturnos ameaçadores. Um complicado e frustrante relacionamento com uma mulher casada leva o poeta a concluir que a "vida normal' não era para ele" (Bakich 41); coincidentemente, seus poemas passam a formular maneiras de se escapar das fraquezas do corpo e do espírito. O fazer poético proporciona ao eu lírico um desvio das tentações, uma razão para viver e um consolo. Mas, àquela altura, a literatura parece não ter sido suficiente para estancar os desejos de Pereliéchin, que em 1937 entra para o monastério ortodoxo. Imagens da vida monacal aparecem como uma rota de fuga: "veja quão abençoados / são os corações e os lábios / que dia e noite / estão em busca de Cristo" (Bakich 43).

A disciplina monástica, que mais tarde será identificada por Pereliéchin como uma segunda fonte de prazeres estéticos, não vai impedir, no entanto, que o jovem adote uma postura ambígua em relação às tentações sensuais e que mantenha ao longo dos anos de atuação como sacerdote encontros fortuitos e ligações amorosas com homens. Como ele escreve no soneto "Amendoim," "nas ruas de Pequim, Xangai, Tientsin" "[...] eu gozava as noites de motim / Aprisionando os sermões nas estantes / Para aventuras, encontros picantes / Na avenida, na praça, no jardim" (40). Entre o sacerdócio e "as noites de motim," sua condição dual- "meu destino tem sido fraturado desde a infância" (Bakich 22) - vem expressa em diversos poemas de sua fase chinesa, numa ânsia pela iluminação divina:

Eu sou uma pirâmide. Eu sou o topo -

Uma janela-Olho no azul, Admiro o sol sobre a planície, 
Corrida de relâmpagos, tempestades de dança.

E abaixo - salões lúgubres

Sempre frios e escuros.

E mais profundos - esconderijos, porões

$\mathrm{Na}$ areia estão meio enterrados. (Rannit 90)

Na continuidade do poema, o eu lírico, em busca de redenção, vai propor que se inverta a pirâmide. Contrariando as leis da física (a sua pulsão sexual?), sugere equilibrá-la apoiada em seu vértice, para que se exponham à luz divina os escuros cômodos, até então subterrâneos. Anos mais tarde, porém, Pereliéchin vai acatar a sua geometria queer e encontrar meios de celebrá-la e validá-la, inserindo-a numa tradição mítica, literária e histórica de relações homoeróticas incorporadas em seus versos: Zeus e Ganimedes, Sócrates e Alcibíades, Adriano e Antínoo, Shakespeare e o hipotético Willian Hughes, Verlaine e Rimbaud, Verlaine e Lucien Létinois, Stephan George e Maximilian Kronberger, Oscar Wilde e Bosie. Irmanando-se a outros, pôde compreender e assumir sua constituição erótica e emocional e, por meio dessas afinidades eletivas, criou para si uma linhagem literária. Já não queria reprimir-se ou modificar-se, e pôde permitir que a energia dos recônditos mais profundos, "meio enterrados," de sua psique viesse à tona e se tornasse força motriz de sua vida pessoal e de sua produção poética.

Em vez de propor uma divisão vertical do corpo piramidal, entre "alto" e "baixo," com sua óbvia hierarquia simbólica entre "claro" e "escuro," o "aceitável" e o "inaceitável," como acontece em "Pirâmides," o eu lírico dos poemas de Pereliéchin passa a vislumbrar integridade onde só havia polaridade e dissociação. Encontra na imagem do canhoto a maneira de representar seu corpo, sua sexualidade e sua afetividade. A oposição do canhoto ao destro não consiste em uma dilaceração interna, mas numa oposição ao mundo externo: não é mais da ordem do defeito, mas da diferença. Seu estar no mundo e sua especificidade de gênero em relação aos outros seres humanos é representada lateralmente-num eixo horizontal e, portanto, em princípio não hierarquizado. Essa figuração "canhota" da identidade homossexual se torna um tópos na poética de Pereliéchin a partir da década de 1970. Serve para contrapor o indivíduo à norma coletiva, dramatizando, por meio de diálogos poéticos, a resistência ao discurso social disciplinador dos gêneros que regula a rotina da 
vida de quem, afeito à heterossexualidade, "não olha além":

— “Assim não dá! Tu deves escrever

Com outra mão, ou ficarás sem nada.

Qualquer mister, tarefinha qualquer

Para o canhoto é cousa complicada.

Viver é bom-somente para quem

Se mistura com outros, não se isola,

Que, caminhando aqui, não olha além

Do seu trabalho, do bife, da bola.

Há graça nos bailes de carnaval,

Na conversa leviana sem mistério

E no puxar a mulher do rival

Pelos alegres bosques do adultério."

- Bem entendi, que homem normal é rei,

Mas sou canhoto, e o continuarei. (Bakich 9)

Aferrar-se ao canhotismo equivale a uma profissão de fé na identidade homossexual e no direito de existir como tal, ainda que o poeta seja assolado por afetos contraditórios (desejo, rejeição, inveja, frustração, solidão, saudade) e pela consciência do estigma que pesa sobre os que se desviam da norma social ("trabalho," "bife," "bola").

$\mathrm{Na}$ fase brasileira da poesia da Pereliéchin persistem projeções da homossexualidade plenamente negativas, como "aleijões," "podridão" e "lodo lascivo". Entretanto surge o sentimento de que "o canhotismo espiritual é bonito" e que a discriminação será recompensada no Juízo Final, quando os canhotos se sentarão "[...] à esquerda de Cristo / E abaixo, à direita / os destros ficarão nos piores lugares" (Bakich 214). Essa atitude positiva em relação à homossexualidade franqueia o exercício do jogo homoerótico e a busca de satisfação sexual livre das regras da monogamia e da heterossexualidade:

Nas noites feiticeiras de luar

Sofro horas nervosas, enquanto a lua

Compele-me para a tortuosa rua 
Das saunas - mas não para me banhar.

$\mathrm{Na}$ Sodoma ardente do lupanar

$\mathrm{O}$ vapor quente agita-se e flutua,

Destacando a nudez. Ninguém recua

Aos caprichos da fortuna e do azar.

Sou de todos. Todos se tornam meus,

E cada um se transforma em semideus

Nas nuvens densas, prenhes de clarões.

... Saio de lá com a carne esgotada

E, já na cama, exsudo confissões

Aos primeiros reproches da alvorada. (Bakich 48)

Da vivência da "carne esgotada" e de um discurso poético que rebaixa a procriação heterossexual a uma hereditariedade maculada ("Tu terás filhos, herdeiros de eczemas / [...] / E eu terei mais um caderno de poemas") demarcase uma trincheira a partir da qual aquele que transgride as convenções de gênero pode contestar o mundo tal como está ordenado pelo reinado do "homem normal," que promove o heteropatriacalismo e dele naturaliza o que melhor the convém. O que incluiu não só "puxar a mulher do rival / Pelos alegres bosques do adultério," como também servir-se hipocritamente das relações homossexuais enquanto mantém os laços heterossexuais que lhe garantem os privilégios da conformidade aos valores hegemônicos. Pereliéchin registrou tais ambiguidades da masculinidade latina e captou a fluidez com que a homossexualidade se define no Brasil a partir de categorias do binarismo herteronormativo: os "bofes" ativos são considerados heterossexuais e, nesse papel, podem escamotear sua homoafetividade (Green 27). Como sintetiza João Silvério Trevisan, no Brasil, o machismo é "uma forma exuberante de buscar a homossexualidade" (31).

A poesia de Pereliéchin propõe uma outra ordem de coisas. Em "O discurso de Aristóteles" projeta-se poeticamente uma idade de ouro em que o binarismo de gênero estava mediatizado por um irreverente terceiro sexo, um "lascivo 'ele/ela"' que afrontava os deuses: 
Aquela raça de gente tinha uma força incomum

Era arredondada de forma e ligeiramente engraçada

Eles não ofereciam aos deuses o que lhes era cabido

E por esse erro foram divididos em dois. (Moss 190)

Observe-se no poema que a duplicidade do "ele/ela," longe de ser um problema, indica, ao contrário, um "terceiro sexo" íntegro e saudável. A mutilação advém de não mais poder viver em harmonia essa dualidade original. Uma vez cindido, o terceiro sexo entra em crise, reprime sua natureza sexualmente fluida e reitera hipocritamente a norma heterossexual: "invade as capelas matrimoniais / antecipando atraentes adultérios; / Conquista mulheres numa pilhagem, e então / sustenta crianças e canta loas para si mesmo" (Moss 190). Pereliéchin sabia do que falava: como se lê em seus poemas e se confere em sua correspondência, por mais de uma vez em sua vida envolveu-se com homens casados, pais de família, e sofreu a dor de se ver preterido. Como no caso de Eugenii "Zhenia" Vitkovskii-o Ariel moscovita de seus poemas, com quem Pereliéchin nunca se encontrou pessoalmente e que, ao em vez de aceitar os convites de Pereliéchin para que fosse visitá-lo no Rio de Janeiro, trocou a família por um novo casamento e teve novos filhos: "Como uma estranha bênção que recai sobre nós / Nosso beijo é cheio de fogo e paixão frenética / No entanto, eu sei: está chegando o tempo / Quando terei de escolher seu presente de casamento /[...] / E como o mar, restarei sozinho" ("O inevitável," Ly e Sylvester).

Optando por outro caminho, em alguns momentos Pereliéchin lamenta e questiona a submissão dos canhotos ao mundo dos destros. Quando escreveu o relato autobiográfico Poema sem um assunto, Pereliéchin alertou que sua crônica não agradaria a tios e tias: "por mais de cinquenta anos nós não nos demos bem, os reprodutores e eu" (Leyland, "Valery Pereleshin" 183). Em vários poemas, Pereliéchin deplora o coito reprodutivo e a constituição da família como o único corolário das relações amorosas:

Será que não há fertilização

Sem que o casal pratique despudores,

$\mathrm{Na}$ terra cheia de ondas e de cores,

De espelhos, de reflexos da canção? 
Acoplando-se, duas nuvens quentes

Dão vida aos inúmeros descendentes:

Musgos, ervas, pássaros, animais.

Dois espíritos, dois Ariéis celestes

Criam também sonetos - os teus e estes,

Os arco-íris para os olhos mortais. (Bakich 46)

Ao seu modo, os poetas canhotos, como as nuvens, geram descendência de outra natureza. Pereliéchin resiste nesses momentos àquilo que Lee Edelman chamou de "futurismo reprodutivo," tirânica ordem simbólica e política que, em nome de um "mundo melhor," salvaguarda a heteronormatividade como promotora e protetora do futuro, e a Criança como merecedora de todas as atenções sociais. Consequência lógica, segundo Edelman, a homossexualidade-que não se submete necessariamente ao imperativo da reprodução-é discriminada (e muitas vezes incriminada) e entendida como uma espécie de sociopatia, uma sintomossexualidade que vem negar a idealização do futuro e "insistir no acesso ao prazer em vez de o acesso ao senso" (37).

Nesse mesmo sentido vai a poesia de Pereliéchin: em "Um conselho," o eu lírico, "com irônico sorriso" desconstrói a narrativa bíblica arquetípica do heteronormativismo no Ocidente. Qual uma serpente a tentar Eva, o eu lírico alerta o amado sobre os riscos que ele corre de comprometer o seu futuro (a sua gleba no paraíso) em função de uma relação homossexual:

O teu Éden na margem deste rio

Verias desabitado e sombrio,

A mata transformada num deserto

Sem balbuciar de crianças, sem brinquedos

Vais permitir que fique assim tão perto

O destrutor dos divinos vinhedos? (Bakich 53)

No entanto, em "Incorporação," a força corruptora do relacionamento homoafetivo é complementada pela potência criadora, para o poeta, menos mortal, que advém daqueles que são, para todos os efeitos, "infecundos": "Filhos, 
netos? Não, serás infecundo: / Atingindo outros alvos, outras metas, / Menos mortal achar-te-ás neste mundo!" (Bakich 51).

Colocar-se fora da lógica do futurismo reprodutivo - assumir o canhotismo existencial, nos termos de Pereliéchin-é para Edelman um mecanismo de resistência à ordem heterossexual. Também o é para Pereliéchin, mas de maneira talvez mais branda e certamente pouco triunfante. No universo do poeta persiste a consciência — e certa aceitação amarga — de que a ordem heterossexual não é facilmente suplantada, que "a lei da vida é dura e não se altera":

Amo teu corpo formoso, meu Joel

Que cheira a sol, à jovem primavera

Não discordo da prazenteira Vera,

Que o julga mais nutritivo que mel.

Entendo que não me podes ser fiel,

Que a lei da vida é dura e não se altera

Que logo virarei uma quimera

Supérflua no idílico painel.

Não luto contra a tua natureza, Respeito-a, deixando-te na certeza, Que, quando penetrares a Nadir,

Lá na Barra, no momento do orgasmo, Não farão falta, no teu entusiasmo

As sementes que acabo de engolir. (Bakich 22)

Tal respeito pela heterossexualidade alheia é em parte uma capitulação à norma social, mas sobra ainda um cínico olhar. $\mathrm{O}$ eu lírico não neutraliza o seu desejo de sedução nem espanta de todo o devaneio narcísico do triunfo sobre a mulher rival por meio de uma outra espécie de reprodutividade, possível graças ao "útero alegórico" (Bakich 17) do fazer poético: Quero-te para mim. Então esquece / A noiva, diz-lhe que 'tudo acontece,' / Que não desejas nem filhos, nem netos, // Que neles não é muito que tu perdes, / Mas, multiplicados nos meus sonetos, / Serão mais salvos os teus olhos verdes! (Leyland, Gay Roots, 648). 


\section{Conclusão}

Se a poesia como refúgio é um lugar-comum da lírica universal, em Pereliéchin a imagem ganha contornos e simbolismo específicos. A poesia oferece-lhe um território alternativo, onde pode no presente viver afetos e desejos homoeróticos (os encontros entre "Ariéis"), constituir um passado (recuperando as narrativas de casais homossexuais notórios) e conceber uma resposta diferente ao imperativo de futuro e de fertilidade representado pela repro-sexualidade (Lopes 139): a criação poética, onde se multiplicam os olhos do amado e se alcança uma existência menos mortal. Nessas três dimensões temporais - passado, presente e futuro - o território homopoético bem poderia compensar a instável situação de um emigrado: no reino da homossexualidade e da poesia, Pereliéchin encontra raízes, estabelece vínculos e prepara a posteridade.

Sabe-se que as identidades individuais, tanto quanto os papeis sociais que se assumem, são porosos e suas múltiplas camadas mutualmente interagem. Portanto, a identidade homossexual de Pereliéchin dificilmente deixaria de interseccionar-se com sua condição de "duplo" emigrado. E vice-versa: como emigrado, sua homossexualidade certamente influiu no modo e nos limites de sua inserção social. Dessa forma, não surpreende que Pereliéchin se valesse do território da Poesia para sintetizar a complexa geometria existencial como "pária," tratando também do seu percurso transnacional, onde se cruzam tempos e espaços: "Eu servi honestamente três terras-mães" (Bakich 149), escreve o poeta. Por mais que Pereliéchin mantenha conexões emocionais, muitas vezes doloridas, em relação a cada um dos três países que considera "terras-mães," sua poesia expressa sobretudo a experiência do transitório e do atravessamento: “TransFronteira, TransExterior, / TransApátrida, TransExílio, / TransGrandeOceano, / TransBrasil, TransPlaneta, / TranSéculo-Vinte" (Bakich 157).

Essa trajetória o tornou, talvez, menos comprometido com o discurso patriótico e menos limitado pelos laços de afinidade a uma comunidade nacional específica. Em "Inevitável," o eu lírico se apresenta destituído de "raças, castas, crenças," se vê como um mar, amplo e solitário, "refletindo, fatigado, auroras estrangeiras," liberado dos mecanismos de fechamento e segregação: "Há muito superei todas as formas de divisão / De língua, e de sangue, e até de raça, / E todas essas velhas paredes e grades / Com que o homem cerca seu próprio espaço" (Bakich 131). 
Nessas condições, está apto a lançar um olhar queer para a narrativa da nação e sua correspondente "religião cívica" (Chauí 18), questionando a homogeneização que alimentou por muito tempo a ideologia nacionalista, sobretudo nos casos de sistemas totalitários: segundo Pereliéchin, os poetas canhotos "têm uma visão diferente do mundo. Eles estão livres dos cortes de cabelo fascistas, todos no mesmo estilo, do filisteísmo, do pensamento padronizado" (Bakich 215). Pereliéchin, apátrida e negando-se a compartilhar o projeto de futuridade heteronormativo, distingue-se da massa padronizada e manipulável e pode então filiar-se aos "rebeldes, eunucos e monges destituídos" que vivem a condição, sofrida mas redentora, da expulsão:

O destino dos homens é arranjar esposas,

Depois filhos, filhas e por fim netos.

Então, por meio deles, aprendem o $\mathrm{ABC}$,

Bufam e misturam os tempos verbais.

Mas será que um homem de fé, um cientista, um asceta,

Ou então um poeta que envelopou seu sofrimento secreto

Em sons e pausas, repentinamente vai

Por esse caminho espalhar suas sementes?

Pelo fado e pelo perdão divino, são poupados

De noivas virgens e alcoviteiras -

Tanto Lermontov, e Marlowe, e Verlaine

Desprovidos de um lar, eles guiaram suas carruagens, Ao longo das paredes que se fecham e resistem o inverno -

Os rebeldes, eunucos e monges destituídos. (Moss 192)

Monge (auto)destituído, repetidamente desprovido de um lar, Pereliéchin podia compreender bem os rebeldes, ainda que não fosse um. Seu "sofrimento secreto," uma vez desenvelopado, permitiu-lhe vislumbrar uma ordenação do mundo concorrente à que existe. Seus fracassos (inclusive sua inaptidão para garantir o próprio sustento) se contrapõem à associação entre heteronormatividade, sucesso e avanço. Refletem, assim, uma lógica queer, ou contrahegemônica que, para 
Judith Halberstam, associa "fracasso com inconformidade, práticas anticapitalistas, estilos de vida não reprodutivos, negatividade e crítica" (89). No território dissidente da poesia, Pereliéchin ganhou nova pele, aprendeu novos idiomas e intensificou sua voz poética. Pôde adotar outras terras e combinar novas identidades, revisitar os países que nunca mais voltou a ver e celebrar o prazer dos corpos, o seu e o de outros homens. E acreditava ter aberto um caminho no Brasil para poetas russos como Kuzmin e ele mesmo:

Aqui todo estrangeiro é desejado

Para mim, o novo mundo brilhou

E eu, o antigo Irkutskiano,

Deixei de amar meu lago Baikal.

Gradualmente virei um mulato

(Sal marinho e calor)

Ganhando um moreno

Tom no pálido rosto

Não espanta! Tantos sorrisos,

Todos os amigos na varanda.

Escrevo poemas sem erros

Em Português.

Mas isso não é tudo:

O caminho de um país ensolarado

Eu abri para poetas russos -

Para mim e para Kuzmin. (Tri rodiny 153)

Esse caminho, na verdade, está ainda para ser trilhado. O teor contestatório da poesia de Pereliéchin mantém-se em estado latente, à espera de leitores. Só então sua poesia poderá cumprir sua potencial função política ao ampliar, sem pudores, o arquivo de representações literárias dos papéis e desejos sexuais, desafiando a rigidez das dualidades que, com ímpeto ainda hoje, aprisionam a fluidez da sexualidade humana e rechaçam a homoafetividade. 


\section{Obras citadas}

"A língua portuguesa nos versos de um poeta russo." O Estado de S. Paulo, 23 set. 1983, p. 15.

Bakich, Olga. Valerii Pereleshin: The Life of a Silkworm. U of Toronto P, 2015. Berlant, Lauren G., and Lee Edelman. Sex, or the Unbearable. Duke UP, 2014.

Carvalho, Lucas Borges de. O controle público sobre a programação da TV no Brasil: entre a censura, a democracia e a liberdade de expressão. 2015. U de Brasília, Tese de doutorado, docs.ndsr.org/docteselucasborges.pdf.

Chauí, Marilena. Brasil-mito fundador e sociedade autoritária. Fundação Perseu Abramo, 2000.

Edelman, Lee. No Future: Queer Theory and the Death Drive. Duke UP, 2004.

Green, James N. Além do carnaval: a homossexualidade masculina no Brasil do século $X X$, tradução de Cristina Fino e Cássio A. Leite, U Estadual Paulista, 2000.

Halberstam, Judith. The Queer Art of Failure. Duke UP, 2011.

Hinrichs, Jan Paul. Introduction. Russian Poetry and Literary Life in Harbin and Shanghai, 1930-1950: The Memoirs of Valerij Perelešin. Rodopi, 1987, pp. 9-23.

—. Valerij Perelešin (1913-1992): Catalogue of His Papers and Books in Leiden University Library. Leiden U, 1997.

Ivask, Yurii. "Ob avtore." Ariel de Valério Pereliéchin, 1976, pp. 3-7.

Junqueira Ivan. “Acertos e equívocos.” Jornal do Brasil, Caderno B, 25 Junho de 1983, p. 10.

Karlinsky, Simon. "A Hidden Masterpiece: Pereleshin's Ariel." Christopher Street, vol. 2, no. 6, 1977, pp. 37-41.

-. "Russian Culture in Manchuria and the Memoirs of Valery Pereleshin." Freedom from Violence and Lies: Essays on Poetry and Music by Simon Karlinsky, edição de Robert P. Hughes et al., Academic Studies, 2013, pp. 310-20.

Leyland, Winston. "Valery Pereleshin (1913-1992)." Out of the Blue, Russia's Hidden Gay Literature, edição de Kevin Moss, Gay Sunshine, 1997, p. 183.

-, editor. Now the Volcano, An Anthology of Latin American Gay Literature. Gay Sunshine, 1979.

_, editor. Gay Roots, Twenty Years of Gay Sunshine. Gay Sunshine, 1991. 
Li, Meng, e Richard D. Sylvester. "Valerii Pereleshin at the International Poetry Festival in Austin, Texas (April 1974)." Toronto Slavic Quarterly, vol. 14, 2005, sites.utoronto.ca/tsq/14/sylvester14.shtml.

Lopes, Denilson. O homem que amava rapazes e outros ensaios. Aeroplano, 2002.

Mattoso, Glauco. "O misterioso poeta Pereléchin.” Lampião da esquina, vol. 2, no. 17,1979 , p. 14.

Moss, Kevin, editor. Out of the Blue, Russia's Hidden Gay Literature, Gay Sunshine, 1997.

Pereliéchin, Valério. "Cruzeiro do Sul." Jornal do Brasil, 5 ago. 1978, p. 5.

—. "Letters to P. P. Lapiken." New Magazine, no. 234, 2004, magazines .russ.ru/nj/2004/234/per7.html.

—. Nos odres velhos. Achiamé, 1983.

—. "Pushkin's Gay Poem." Gay Roots, Twenty Years of Gay Sunshine, edição de Winston Leyland, Gay Sunshine Press, 1991, p. 649.

-. "To One Who Confessed." Now the Volcano: An Anthology of Latin American Gay Literature, edição de Winston Leyland, Gay Sunshine, 1979, pp. 264-65.

—. Tri rodiny: desiataia kniga stikhotvorenii. Albatros, 1987.

-. "Twelve Sonnets from Ariel." Out of the Blue, Russia's Hidden Gay Literature, tradução de Vitaly Chernetsky, edição de Kevin Moss, Gay Sunshine Press, 1997, pp. 189-95.

Rannit, Aleksis. “On Valerij Perelešin's Poetry and Poetics: The Poet's First Six Collections (1937-1971)." Russian Language Journal, vol. 30, no. 106, 1976, pp. 79-104.

Schuvaloff, George. "Gay Life in Russia," Christopher Street, vol. 1, set. 1976, pp. 14-23.

Trevisan, João S. Devassos no paraíso: a homossexualidade no Brasil, da colônia à atualidade. Max Limonad, 1986.

Wyler, Vivian. "Quando traduzir pode ser um ato de gratidão.” Jornal do Brasil, Caderno B, 8 set. 1979, p. 11. 